\section{Francesco Bandarin: Las tasas a los servicios turísticos podrían constituir el futuro de la financiación de la conser- vación del patrimonio}

URL de la contribución <www.iaph.es/revistaph/index.php/revistaph/article/view/3772>

Desde octubre de 2015, y con anterioridad entre los años 2010-2014, Francesco Bandarin ejerce la responsabilidad de Subdirector General de Cultura de la Organización de las Naciones Unidas para la Educación, la Ciencia y la Cultura (Unesco).

Arquitecto especializado en planificación urbana y profesor en excedencia de planificación urbana y conservación en la Universidad luav de Venecia, Bandarin acredita una intensa trayectoria académica y profesional como consultor en organizaciones internacionales en materias de conservación urbana y desarrollo.

Entre 2000 y 2010 dirigió el Centro de Patrimonio Mundial de la Unesco y ocupó la secretaría de la Convención de Patrimonio Mundial. Como director del CPM, lideró una amplia red de alianzas públicas y privadas en pro de la conservación del patrimonio mundial y puso en marcha una serie de centros regionales de salvaguardia del patrimonio (llamados centros de categoría 2) en todas las regiones del mundo. Fue director de la Oficina del Plan Especial para la Salvaguarda de Venecia y su Laguna y director de los programas especiales preparatorios del jubileo de 2000 en Roma.

Presidente de la Associazione Nazionale Centri Storico-Artistici (ANCSA) y miembro de la junta directiva de los premios Aga Khan de arquitectura, perteneció durante un tiempo al comité visitante del Getty Conservation Institute. En 2014, fue nombrado presidente del jurado de la Bienal de Arquitectura de Venecia y presidente del jurado de los premios Shenzhen Creative Design (SCDA).

Entre sus recientes publicaciones podemos citar, junto con Ron van Oers, The Historic Urban Landscape: Managing Heritage in an Urban Century (2012) cuya traducción al español, recientemente publicada, aparece recensionada en la sección Reseñas de este número de revista $p h-y$ Reconnecting the City. The Historic Urban Landscape Approach and the Future of Urban Heritage (2015), ambas publicadas por Wiley-Blackwell, Londres. 
revista ph: Al cumplirse 70 años de la fundación de la Unesco, de la entrada en vigor de su constitución y de la primera reunión de la Conferencia General, ¿cuáles son, en materia de cultura y, más específicamente, en patrimonio cultural y natural, los grandes desafíos que tiene planteados la organización de Naciones Unidas?

Francesco Bandarin: Los actos del septuagésimo aniversario de la Unesco han constituido una oportunidad interesante para reflexionar sobre nuestra misión. En realidad, desde 1945, desde el final de la II Guerra Mundial, la misión de la Unesco ha consistido en contribuir a nivel internacional a la consolidación de la paz, la erradicación de la pobreza, el desarrollo sostenible y el diálogo intercultural. Se trata de un cometido extremadamente vigente pero que hay que abordar en el contexto actual de manera diferente, porque el mundo ha cambiado. Por ejemplo, algunas de las preocupaciones actuales, como las recientres migraciones en Europa o la desestabilización social y cultural en el mundo árabe, no eran tan acuciantes cuando se creó la Unesco.

En el campo concreto del patrimonio también se han producido cambios desde hace setenta años. Por un lado, frente a programas más centrados en la restauración, hemos conocido el nacimiento de muchos instrumentos nacionales e internacional -sobre todo estos últimos- que tienen como tarea principal la protección del patrimonio como bienes internacionales, mundiales. Basta citar la Convención sobre la protección del patrimonio mundial, cultural y natural de 1972.

Más recientemente, dichos instrumentos se han extendido al patrimonio inmaterial y el foco de nuestras preocupaciones se ha puesto en temas como la diversidad, la creatividad cultural y las industrias creativas. El respeto a la diversidad cultural supone una nueva mirada sobre el patrimonio, dado que antepone este valor a otros artísticos y culturales más tradicionales. Estas transformaciones, partiendo de la convención del 72 que ejerce de faro, son muy importantes porque ponen de relieve que el concepto de patrimonio no es fijo; al contrario, muda. Y para los próximos 30 años se esperan cambios todavía mayores. El papel de la Unesco consiste en anticipar esas tendencias y actuar de motor de los procesos. revista ph: Deducimos de su respuesta que el cambio no es enemigo del patrimonio, a pesar de algunas resistencias.

Efectivamente, el cambio no constituye ningún enemigo, sino un factor que tiene que ser manejado. Volviendo a la Convención de patrimonio mundial, ¿saben ustedes que en principio fue pensada como la lista de los 100 grandes bienes patrimoniales del mundo, las 100 maravillas del patrimonio mundial? Sin embargo, en 2016, nos enfrentamos a 1031 bienes inscritos. ¡El concepto inicial ha cambiado por completo!

Se han modificado las intenciones iniciales en el número de bienes inscritos y son muchos los países nuevos que presentan sus propias candidaturas. Las tipologías se han ampliado y se incorporan paisajes culturales, itinerarios, patrimonio científico, patrimonio inmaterial...

Pensemos en el volcán Tongariro, en Nueva Zelanda, centro de espiritualidad de los pueblos maoríes. En aquel espacio no hay ninguna construcción humana; se trata simplemente del volcán, en toda su materialidad, con una serie de valores inmateriales asociados. Este constituye un claro ejemplo de inclusión de nuevos elementos que no pertenecen a la concepción clásica del patrimonio y de quiebra de las fronteras entre el patrimonio cultural y el natural. Esa segmentación, de la tradición greco-judaica, no se da en otras sociedades no europeas; por lo tanto, en su superación, se atisban muchas posibilidades de futuro.

Y finalmente, podemos aludir al patrimonio vivo de las ciudades y de los paisajes culturales. Las ciudades suponen en este momento la categoría más amplia en la lista de patrimonio mundial; contamos con más de 300 ciudades frente a los poco más de 1000 bienes inscritos. Esta cifra representa un tercio del patrimonio mundial y la mitad del patrimonio cultural. Paisajes culturales y ciudades introducen el cambio en el concepto de patrimonio mundial, en la idea de conservación.

Como decía al principio, el cambio no es un enemigo sino que tiene que ser manejado porque, de lo contrario, el cambio te cambia. 


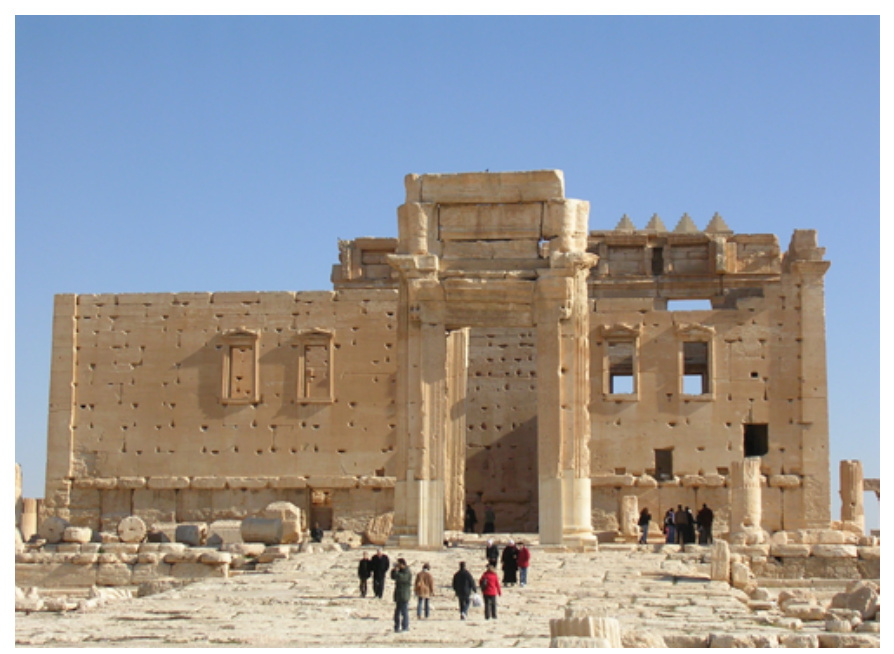

Templo de Baal, Palmira (Siria), 2007 | foto Martín Javier Fernández Muñoz autor de todas las imágenes de la entrevista

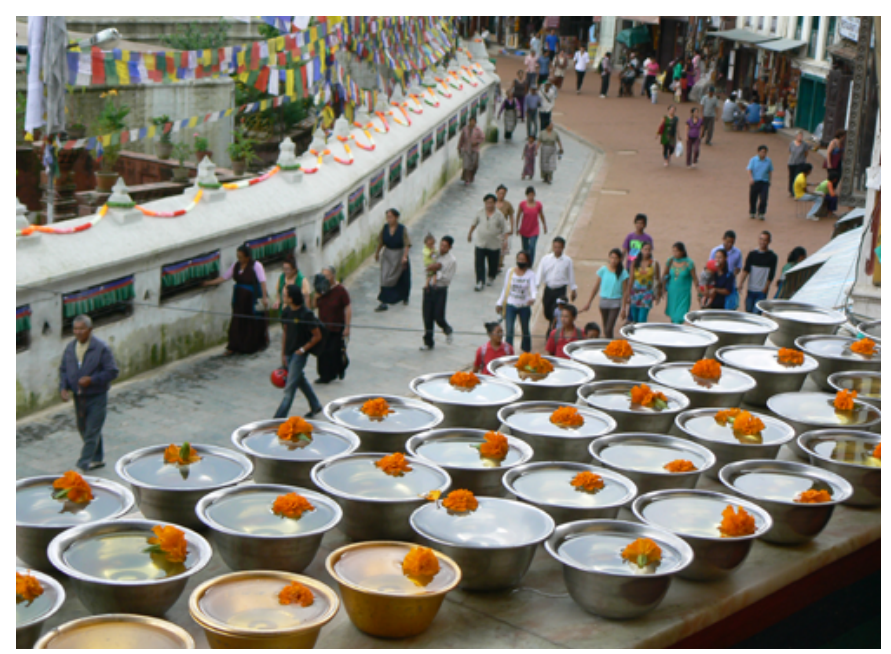

Boudhanath, uno de los lugares sagrados budistas en Katmandú (Nepal), 2011

A pesar de las resistencias, esta interpretación filosófica se impondrá en el futuro, no sólo porque supone dar cabida a los elementos inmateriales, sino fundamentalmente porque otorga peso a la ciudadanía que convive con el patrimonio. Insisto en que esta última cuestión es fundamental en ciudades patrimonio cultural; en caso contrario, no existirían. Los trabajos preparatorios para Hábitat III, la conferencia de Naciones Unidas sobre vivienda y desarrollo urbano sostenible, que tendrá lugar en octubre de 2016 en Quito, nos lo están mostrando de forma clara. El mapa de la conservación del patrimonio

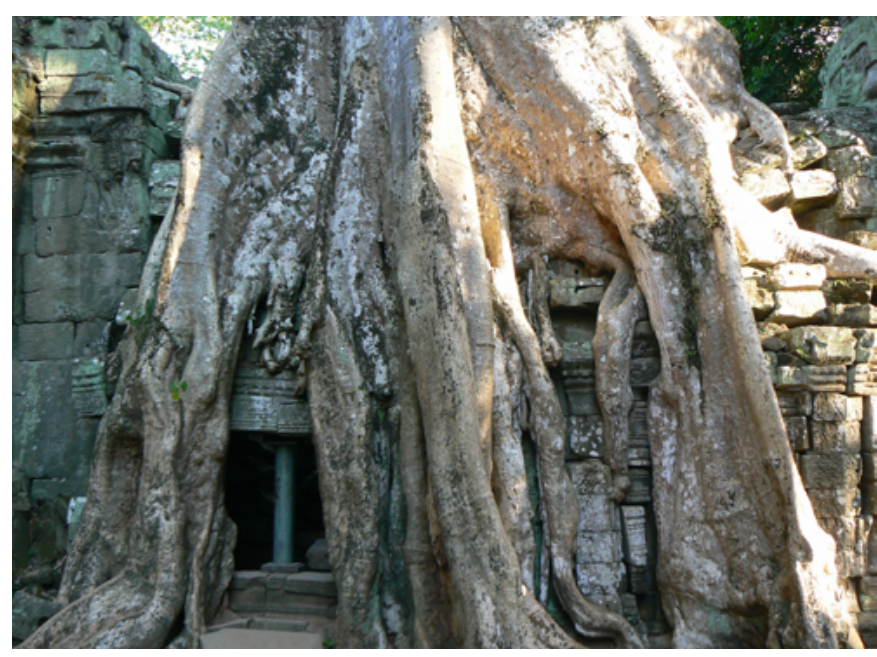

Templo jemer de Ta Prohm, finales del siglo XII, en el complejo de Angkor (Camboya), 2010

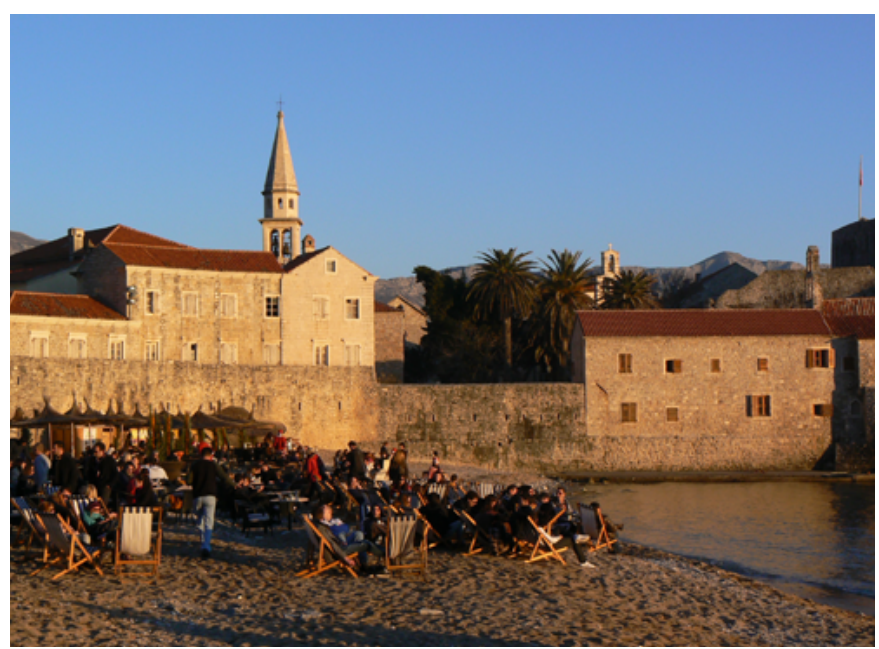

Ciudad costera de Budva, en Montenegro, 2010

urbano en el mundo refleja la importancia de la diversidad, de la transformación social y física y la presencia de valores ligados a lo inmaterial, a las tradiciones, a la memoria.

Estas transformaciones están detectadas y recogidas por la Unesco en la Recomendación sobre el paisaje urbano histórico (2011), el primer texto sobre patrimonio del organismo internacional en los últimos cuarenta años. La tarea se centra ahora en lograr adhesiones a esta visión de futuro. 
revista ph: ¿Qué puede hacer la Unesco para proteger lugares con excepcional valor histórico, artístico, arqueológico o arquitectónico en serio peligro de desaparición en países en guerra o en zonas de conflicto como Siria, Irak, Malí, Palestina o el Congo? ¿Se puede actuar en medio del conflicto? ¿Hay que esperar a que termine la confrontación armada, con el riesgo que ello conlleva de destrucción total?

La Unesco, como acabamos de indicar, es un producto del segundo conflicto mundial; nace como respuesta a la catástrofe global de millones de muertos y de una fuerte destrucción del patrimonio en Europa y Asia, fundamentalmente. Por tanto, la contestación a la destrucción del patrimonio en casos de enfrentamientos armados forma parte de ADN de la institución. En este sentido, no resulta casual que la primera convención (1954) esté dedicada a la protección de bienes culturales en en estas situaciones. Lamentablemente hemos de reconocer que sólo dos tercios de los estados miembros de la Unesco se ha adherido a la conocida como Convención de La Haya, lo que implica que más de 70 países no han firmado todavía el acta. Muchos estados se resisten a suscribir estos documentos que suponen ciertas exigencias a sus militares.

La existencia de estos instrumentos no significa que seamos capaces de bloquear al estado islámico cuando bombardea Siria; esto resulta muy difícil. La Unesco no tiene, por ahora, capacidad de prevención en la destrucción del patrimonio ni de intervención durante los combates; ese papel le corresponde a los ejércitos. Hasta el momento, hemos venido trabajando en la reconstrucción de monumentos destruidos una vez que el conflicto armado ha terminado. Pensemos en Angkor (Camboya), Mostar (Bosnia-Herzegovina) o Bamián (Afganistán), por citar sólo algunos ejemplos.

Sin embargo, en los últimos dos años, ataques y destrucciones como los de Palmira y Alepo nos han empujado a poner en marcha otros programas de actuación previos a la finalización de las hostilidades. Por un lado, tratamos de desarrollar instrumentos de prevención en "zonas calientes", aunque las confrontaciones no siempre sean predecibles. Esta tarea preventiva se realiza en colaboración con los responsables patrimoniales y la población local y afecta a los movimientos de piezas de museos, a la creación de zonas de protección patrimonial, al establecimiento de observatorios para garantizar información actualizada, a la vigilancia del tráfico ilícito por parte de policías y funcionarios de aduanas... No resulta fácil porque el frente es amplio; en los últimos años se han simultaneado 7 u 8 confrontaciones, con grandes tragedias humanitarias, y los recursos son limitados.

Al mismo tiempo que en la prevención, estamos operando con las fuerzas armadas de distintos países, que han ido adquiriendo en los últimos años conciencia de la importancia de proteger el patrimonio en casos de guerra. Ejércitos como el británico y el estadounidense cuentan con cualificados departamentos que se ocupan del patrimonio y en Estados Unidos, por ejemplo, para ascender en determinados grados del escalafón militar es necesario un test sobre patrimonio. Constituye toda una novedad esta colaboración con el ejército de los estados miembro y también con las fuerza de pacificación de Naciones Unidas, que son las que actúan en el campo de batalla. Sin olvidar, por supuesto, a organizaciones humanitarias como Cruz Roja.

Sin ir más lejos, en la Conferencia General de la Unesco de noviembre de 2015 se aprobó el refuerzo de nuestra labor en materia de protección de la cultura y promoción del pluralismo cultural en caso de conflicto armado -y también en situaciones de desastre natural, añadiría yo- y se subrayó la importancia de la total coordinación y colaboración de los Estados miembro con capacidad para prestar su ayuda en esta materia a países terceros envueltos en confrontaciones armadas. Con Italia se ha firmado un acuerdo y este país ha puesto a disposición de la Unesco una fuerza internacional para responder a catástrofes naturales o conflictos. Con España estamos en conversaciones y esta posible colaboración se podría extender a unos 10-15 países. Se trataría de reforzar los recursos propios y la ayuda que puedan prestar terceros frente a los desastres.

revista ph: Algunos informes de la Unesco señalan cómo ha aumentado el impacto negativo del turismo de 
masas en los últimos veinte años. ¿Se pueden hacer recomendaciones para una mejor gestión institucional válidas para todos los países? ¿Qué puede suceder en unas décadas si se apuesta todo a la carta del turismo cultural?

Para evaluar esta cuestión, hay que partir, en mi opinión, de una visión positiva del turismo. Este fenómeno de la modernidad ha permitido que miles y millones de personas que circulan por todo el mundo accedan al patrimonio. El turismo no es sólo fuente de riqueza económica y empleo sino también un poderoso motor de intercambio cultural.

Por el contrario, el turismo puede ser muy destructivo tanto para el patrimonio en sí, como para la comunidad que lo sustenta. Pienso en China, un país en el que recientemente visité algunos pueblos de montaña de difícil acceso, que se han desarrollado autónomamente y se han mantenido íntegros, magníficos, a lo largo de la historia. Poco a poco el turismo va llegando y lo que se ha preservado como auténtico se torna falso. ¿Y qué está ocurriendo con ciudades como Venecia, mi lugar de origen, con 27 millones de turistas anuales, lo que significa una tasa de dos turistas frente a un residente local? Es una ciudad invadida; uno pasea por la mañana para tomar un café y no sabe si se encuentra en Venecia o en un pueblo turístico americano.

Paradójicamente, el Ayuntamiento de la ciudad de los 27 millones de visitantes se encuentra en bancarrota, es insolvente; no hay suficiente presupuesto para atender los servicios básicos. Aquí tenemos un problema serio, muy complejo: cómo captar ese torrente de recursos económicos procedentes del turismo para contribuir a la conservación del patrimonio. Este es el quid de la cuestión. Si no somos capaces de revertir esta situación, de gestionar equilibradamente recursos locales, presencia masiva de turistas y necesidades de las personas que habitan los espacios patrimoniales, estamos poniendo al patrimonio en una situación de serio peligro de desaparición; estamos condenando a las ciudades a catastróficos procesos de gentrificación y a que se conviertan en escenarios para el turismo, en vez de en espacios habitables. Hay que equilibrar el manejo de la visión cor- toplacista, inmediata, del turismo, con la visión y la inversión a largo plazo que exige el patrimonio. Lamentablemente, los gestores locales no siempre cuentan con los instrumentos adecuados para ello, aunque puedan estar concienciados del problema.

revista ph: Usted defiende un papel de la cultura mucho más importante en la estrategia global del desarrollo y de la sostenibilidad; reivindica la cultura como un sector importante para la economía y la igualdad social y no un simple lujo o entretenimiento. ¡Pero qué difícil es atraer inversiones para el sector patrimonial! ¿Qué aspectos habría que trabajar para lograr este objetivo en un país como España?

En primer lugar, hay que reconocer que en los últimos 50 años la inversión pública en patrimonio cultural se ha multiplicado por mil, por mucho que la masa financiera destinada a la conservación nos parezca insuficiente. Pero la crisis financiera ha llevado a los estados a su capacidad límite para financiar proyectos en materia de patrimonio cultural, por lo que es necesario encontrar fórmulas alternativas. El sector secundario, la industria, también tiene sus restricciones en materia de financiación cultural y las exigencias gubernamentales en este sentido generan muchas protestas, a las que los políticos son muy sensibles. Quizás la solución pueda venir del sector terciario, que vía tasas a los servicios turísticos (estancias hoteleras, compra de billetes de avión...) podría compensar el desgaste en infraestructuras generales y bienes patrimoniales que el consumo cultural provoca. Obviamente hace falta explicar bien a la ciudadanía el fondo del problema que desarrollábamos en la respuesta anterior; hay que hacer una intensa labor de educación cívica para que esas tasas sean asumidas y no generen rechazos. O empezamos a actuar en este sentido, como está haciendo Francia, o en la próxima década vamos a encontrarnos con graves deficiencias estructurales.

revista ph: Como probablemente conocerá a través de Nuria Sanz, actual directora y representante de la Oficina de la Unesco en México y colaboradora del IAPH desde hace muchos años, el Instituto Andaluz del Patrimonio Histórico ha estado trabajando intensamente en 
el concepto de paisaje histórico urbano y su aplicabilidad en la ciudad de Sevilla ${ }^{1}$. ¿Cómo percibe la aportación del IAPH? ¿Por dónde se ha de seguir investigando y avanzando?

El Instituto Andaluz del Patrimonio Histórico es una organización muy poderosa a nivel regional que debería tener una relación constante con Unesco y colaborar con nosotros en distintas comisiones y áreas que se ocupan del patrimonio. Tal y como hicimos, en efecto, para hablar de ciudad y paisajes históricos. En realidad, más que ser o no cabecera de un sistema que se ocupa de la educación, la ciencia o la cultura, a la Unesco le importa tejer una red extensa de partenaires, en la que cada nodo aporte a los demás su saber hacer y buenas prácticas para una mejor gestión de los temas que tenemos en común. Esta capilaridad de funcionamiento de la organización se detecta en la multiplicidad de cátedras, centros, clubes, comisiones Unesco que se han creado en muchos países del mundo.

En cuanto al concepto de paisaje histórico urbano, en el que venimos trabajando juntos desde los años 20062007, tenemos que revisar y actualizar algunas ideas. Los estudios previos a la reunión Hábitat III, que anteriormente hemos comentado, señalan la existencia de 50 megalópolis en los próximos 30 años. ¿Dónde está el patrimonio en dichas megalópolis? ¿Es posible que el patrimonio no exista en una ciudad como São Paulo? Decir que ciudades con 20 millones de habitantes no tienen patrimonio resulta cuanto menos extraño. Hay que reflexionar sobre ello, sobre lo que la gente identifica como patrimonio; sobre las nuevas formas de patrimonio ligadas a elementos materiales locales que se suman a las formas clásicamente consideradas; sobre la producción de patrimonio para dar satisfacción a los millones de personas que se incorporan a entornos urbanos.

En el fondo se trata de profundizar en la raíz del concepto de patrimonio histórico urbano, que surge de dos fenómenos producidos en los últimos 30 años: la democratización y la globalización del patrimonio. El patrimonio ya no está definido o delimitado por expertos sino por las comunidades; comunidades que hacen evolucionar el concepto de patrimonio y que nos ofrecen distintas

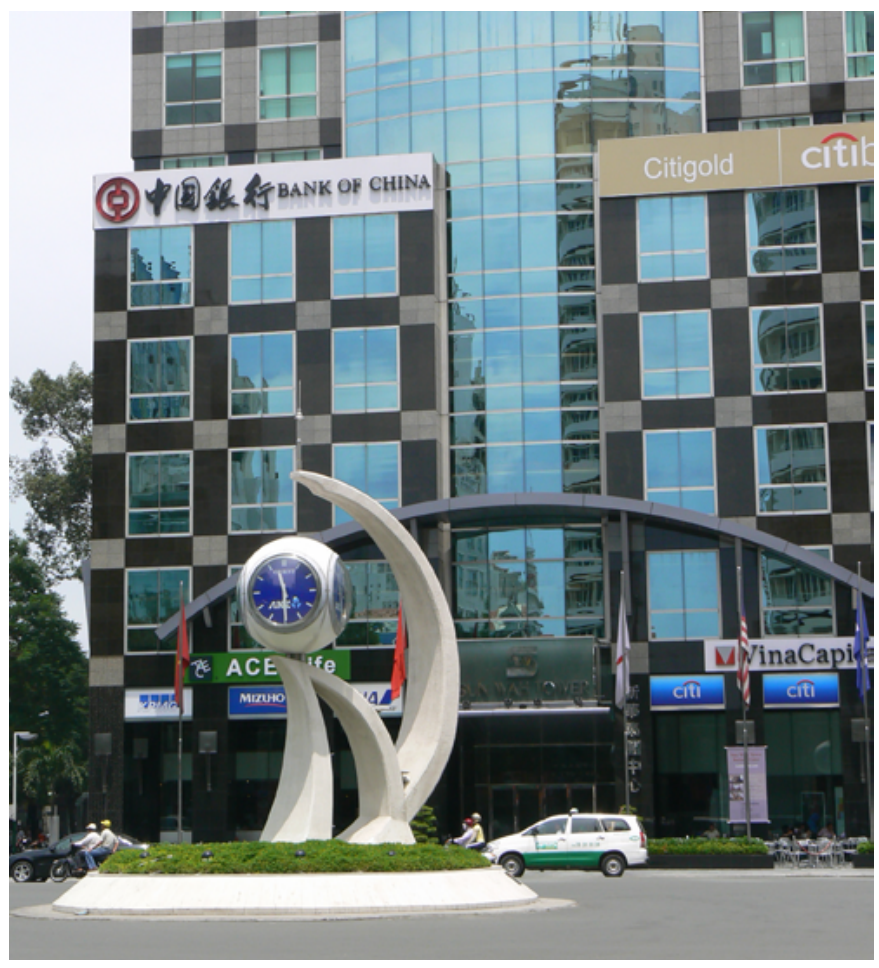

Inmenso reloj Seiko en plaza de Ho Chi Ming, Vietnam

maneras de mirarlo, de utilizarlo, de conservarlo. No hay un pensamiento único en torno al patrimonio, aunque esto para los europeos resulte difícil de aceptar.

En 2017 queremos poner en común estas reflexiones y convocar una conferencia sobre patrimonio y megalópolis para poner en contacto ambas realidades y crear un arco voltaico de tensión. Nos interesa que esté presente no sólo el ámbito académico sino también todos los agentes que actúan sobre el terreno y que posteriormente van a influir en la toma de decisiones. Esperamos contar con ustedes.

\section{NOTA}

1. Guía del paisaje histórico urbano de Sevilla: <http://uww. iaph.es/web/canales/patrimonio-cultural/guia_paisaje_ historico_urbano_sevilla/contenidos_guia_paisaje_historico_ urbano_sevilla.html>. 